\title{
Case Study in Otitis Media: The Corrective Aspect of Craniosacral Fascial Therapy
}

\section{Barry R Gillespie*}

The Family Hope Center, Norristown, USA

\section{Introduction}

Otitis media is an inflammation of the middle ear caused by an infection. Three out of four American children experience otitis media by the time they are three years old [1]. Ear infection is the number one reason parents bring their children to the medical doctor [2].

Current treatment is the administration of antibiotics to kill the bacteria that cause the problem. If a child has multiple ear infections, myringotomy may be required to lessening the chance of permanent hearing loss. Chronic infections may cause irreversible damage to the stapes, incus, and malleus. Approximately two million tympanostomy tubes are inserted annually in America; it is the most common surgical procedure for children [3]

Another method of treatment is by manual therapy through the craniosacral fascial system, an integration of the craniosacral and fascial or connective tissue components. This new modality, with its roots in over one hundred years of osteopathic philosophy, can help to mitigate otitis media [4-6].

\section{Literature Review}

In 1899, William Sutherland D.O. discovered that the brain and cranial bones exhibited motion and founded the craniosacral concept [7]. In 1976, John Magoun, Sr. D.O. said the key to the correction of otitis media was restoring the normal motion of the temporal bones due to trauma [8]. Viola Frymann D.O. reported overwhelming success with osteopathic manipulative therapy in her forty years of experience with children having otitis media [9]. Andrew Weil M.D. also highly recommended cranial manipulation for these children [10].

Robert Fulford D.O. felt that the synergy of osteopathic manipulation and proper lymphatic drainage was critical for success in otitis media [11]. In 2006, Erickson et al. presented a case study of a child with recurrent otitis media and upper respiratory illness. This child responded positively to craniosacral therapy as part of an integrated approach [12].

The fascial or connective tissue component of the craniosacral fascial system is a full body web that intertwines and infuses with every structural cell including muscles, nerves, blood and lymph vessels, organs, and bones [13]. John Barnes P.T. found that when the body is traumatized, the fascia can become strained and create many symptoms and conditions [13]. These strain patterns can pull on any structures, including the components of the ears, at up to 2,000 pounds per square inch [14].

Anatomically in the craniosacral fascial system, the cerebrospinal fluid starts its journey in the choroid plexus of the ventricles, gently fluctuates through the craniosacral system, and flows within the cranial and spinal nerve sheaths out into the collagen tubules of the fascia [15]. Researchers have confirmed a unified system by discovering cerebrospinal fluid in these tubules with surprisingly no ordinary ground substance, blood, or lymph present [16].

Many medical doctors agree that consumption of mucous-forming dairy products for children, who cannot properly metabolize them, can be an important contributing factor in pediatric diseases like otitis media [2,17-19]. Mucus plugs can clog the narrow Eustachian tubes and block any exudate draining from the middle ear down into the nasopharynx. The stagnant fluid in the middle ear can then create a breeding ground for bacteria and viruses, resulting in potential middle ear inflammation and infection.

\section{Case Presentation}

\section{History}

A thirteen-month-old boy presented on April 27, 2006 for evaluation. His mother stated that his primary condition was "chronic earaches". He was also allergic to peanuts and eggs; otherwise he was in good health. He was up to date on his vaccinations and has had no allergy immunotherapy.

The pregnancy was uneventful. Since the fetus was in a breech position, her physician performed an emergency caesarean section. The child's Apgar scores were eight and nine, and he left the hospital as a healthy baby.

He had his first ear infection at six months of age in October 2005. From early December until this treatment started in April 2006, he had four earaches in rapid succession. His pediatrician prescribed azithromycin, which worked well for the first infection. Because of tachyphylaxis, the doctor had to prescribe repeated doses of azithromycin and amoxicillin to quell the continuing infections.

He referred him to a specialist at a major metropolitan children's hospital for ear, nose, and throat evaluation. The otolaryngologist recommended myringotomy as soon as he could be scheduled. His mother held off on the surgery to search for a more natural approach.

\section{Clinical findings}

I palpated the child to determine any restriction of the normal motion of his temporal bones. His brain cycle was two seconds, one second in brain expansion and one second in brain contraction. Trauma, which could have occurred in utero, at birth, and/or during childhood, caused his restricted temporal bone motion.

The brain cycle is the amount of "breathing" time in seconds for

*Corresponding author: Barry R Gillespie, The Family Hope Center, 2490 Boulevard of the Generals, Suite 250, Norristown, PA 19403, USA, Tel: 610-2652522; E-mail: drbarryrg@mac.com

Received January 16, 2014; Accepted February 18, 2014; Published February 24, 2014

Citation: Gillespie BR (2014) Case Study in Otitis Media: The Corrective Aspect of Craniosacral Fascial Therapy. J Allergy Ther 5: 162. doi:10.4172/21556121.1000162

Copyright: (c) 2014 Gillespie BR. This is an open-access article distributed unde the terms of the Creative Commons Attribution License, which permits unrestricted use, distribution, and reproduction in any medium, provided the original author and source are credited. 
the brain to fully expand and contract in its inherent motion. A healthy brain cycle in the craniosacral fascial philosophy is one hundred seconds, fifty seconds in brain expansion and fifty seconds in brain contraction. The facial bones, sacrum, and the dural tube also need to move in synchronicity with the brain.

Generally, the longer the brain "breathes", the better it functions. Since the brain and spinal cord that attaches to the sacrum move together to pump the cerebrospinal fluid, the craniosacral system can have a great effect on the neurophysiology of the entire body. As a result, the brain cycle is the key indicator to check how well the craniosacral fascial system is functioning.

The shape of his head was symmetrical with normal temporal bone position. His facial bones, sacrum, and dural tube were tight with no perceptible motion. The muscles and fascia of his neck were not straining on his temporal bones; his oral structures were not a contributing factor.

In structurally assessing the boy's case, I told his mother that he had severe craniosacral fascial strain, which was restricting his normal neurophysiology and outlined a series of thirty-minute treatment visits. The goal was to mitigate the traumatic cause(s) of his otitis media and to eliminate the need for continued antibiotics and myringotomy.

\section{Treatment and Results}

The goal of his first visit in April 2006 was to help his body open his temporal bones and his brain to a higher cycle. The strain in his craniosacral fascial system released nicely, and his cerebrospinal fluid started to flow better. Four weeks later on his next session his mother said that his ears had improved. With more therapy his brain cycle ended the second visit at sixty seconds.

His mother brought him in four months later in September. She reported that his ear infections had not returned during the tranquil summer months. I found that his entire craniosacral fascial system was still functioning well. As the weather changed in November he came down with a cold, and his mother asked me to recheck him. Usually a cold would always lead to an ear infection, but not this time. His craniosacral fascial system was still open, and his brain cycle remained at sixty seconds.

I called his mother in early February 2007 to see how he was doing during the ominous winter cold and flu season. She said that he had been earache free since the craniosacral fascial therapy had started. He recently had a bad cold with a lot of heavy mucus but surprisingly did not have a sequential ear infection. I suggested that his parents eliminate the acidic mucous-forming dairy products in his diet.

His mother cut back a little, but he still had two baby cups of milk, milk on his cereal, and a little cheese everyday. In late February she told me that he had another cold with some ear pain but no apparent ear infection. I found on re-examination that his craniosacral fascial system was still functioning well, and his brain cycle was now at eighty seconds.

Since the dairy products appeared to be a factor in his recurring colds and ear pain, I again strongly recommended to his parents to substitute the dairy products with other foods. After his mother stopped his dairy consumption for three days, he recovered nicely. A synergistic approach, including the craniosacral, fascial, muscle, and dietary components, can be the most effective treatment for children with otitis media.

On January 5, 2008, about twenty months after his initial evaluation, I examined him on a check-up visit. His brain cycle had increased to the accepted one hundred seconds, and his craniosacral fascial system was functioning very well. His mother reported that he had no ear infections during the past year. At his regular medical visits the pediatrician also reported that his ears had been clear and healthy. On a follow-up e-mail in the summer of 2009, his mother reported that he had been very healthy with no further ear infections.

\section{Discussion}

In my thirty years of clinical practice I have found that otitis media in children appears to be strongly related to the function of the craniosacral fascial system. Since all of the connective tissue of the body exists as one continuous web, many other common pediatric conditions such as asthma, headaches, neck aches, strabismus, colic, rhinitis, and gastroesophageal reflux appear to originate, all or in part, from craniosacral fascial trauma [20,21]. Consequentially, a child can develop many chronic conditions from just one traumatic incident such as a difficult delivery. When the strains from the craniosacral fascial system are released over a series of therapy visits, the child can recover from these illnesses and return to health [22].

Physicians are literally correct when they say that children will "grow out of" otitis media. Anatomically in the first few years, the Eustachian tubes are shorter (13 millimeters at birth) and more horizontally positioned (10 degrees to the skull base at birth) in the cranium making it easier for pathogens to pass from the nasopharynx back into the middle ear. The middle ear is normally filled with air to allow for sound transmission from the external ear to the inner ear, which contains the vestibulocochlear (VIII) nerve. At this age the Eustachian tubes are also narrower, allowing for a greater chance of blockage with a mucous plug or inflammatory exudate.

By the age of seven the middle ear has grown significantly to a more superior position in the temporal bone at a 45 degree angle to the skull base; the tube also has become longer to the adult size of 35 millimeters and correspondingly wider. These anatomical changes can now allow any pathological fluid to more naturally drain by gravity from the middle ear down into the nasopharynx.

Most of the children with otitis media also have a distorted position of their temporal bones. One bone is usually internally or medially rotated, and the other bone is usually externally or laterally rotated. On rare occasions both of the bones are either internally or externally rotated. As a clinical finding in otitis media, the positioning of the temporal bones is secondary in importance to their normal motion.

Many children with otitis media can have muscle and/or fascial involvement in their neck. Since soft tissue strain can pull on and restrict the motion of the temporal bones, the adjacent muscles and fascia must be treated to release the pressure on the ear structures. Without this therapy, the craniosacral fascial system may retighten, allowing the otitis media to return. Orthodontic palatal expansion to widen the maxillary bones and make room for the adult teeth may also restrict the craniosacral fascial system and cause otitis media.

By inductive reasoning, checking the motion and position of the temporal bones and treating, if necessary, each neonate may significantly reduce the incidence of otitis media. Each child can be then be monitored at every pediatric well-visit for normal functioning of his/her craniosacral fascial system.

\section{Summary}

The continued success of this integrated method appears to target 
and correct the pathological origin of otitis media. The treatment benefits for this common pediatric condition would have a very positive effect on global clinical practice. A research group needs to conduct a pilot study to investigate and determine the effectiveness of this approach.

\section{References}

1. Rice ML, Zeldow B, Siberry GK, Purswani M, Malee K, et al. (2013) Evaluation of risk for late language emergence after in utero antiretroviral drug exposure in HIV-exposed uninfected infants. Pediatr Infect Dis J 32: e406-e413.

2. Schmidt M (1990) Childhood Ear Infections. Berkley, Ca: North Atlantic Books.

3. Isaacson G, Rosenfeld RM (1996) Care of the child with tympanostomy tubes. PediatrClin North Am 43: 1183-1193.

4. Mills MV, Henley CE, Barnes LL, Carreiro JE, Degenhardt BF (2003) The use of osteopathic manipulative treatment as adjuvant therapy in children with recurrent acute otitis media. Arch Pediatr Adolesc Med 157: 861-866.

5. Kragh JF Jr, San Antonio J, Simmons JW, Mace JE, Stinner DJ, et al. (2013) Compartment syndrome performance improvement project is associated with increased combat casualty survival. J Trauma Acute Care Surg 74: 259-263.

6. Degenhardt BF, Kuchera ML (2006) Osteopathic evaluation and manipulative treatment in reducing the morbidity of otitis media: a pilot study. J Am Osteopath Assoc 106: 327-334.

7. Sutherland W (1939) The Cranial Bowl. Mankato, Minn: Free Press Company.

8. Magoun H (1976) Osteopathy in the Cranial Field (3rdedn) Kirksville, Mo: Journal Printing Company.
9. Rubenstein S (1990) The Osteopathy alternative. East West: 48.

10. Weil A (1995) Spontaneous Healing. New York: Fawcett Columbine: 35.

11. Fulford R (1996) Dr. Fulford's Touch of Life. New York: Pocket Books.

12. Erickson K, Shalts E, Kligler B (2006) Case study in integrative medicine: Jared $\mathrm{C}$, a child with recurrent otitis media and upper respiratory infection. Explore: The Journal of Science and Healing 2: 235-237.

13. Barnes J (1990) Myofascial Release: The Search for Excellence. Paoli, Pa: Rehabilatation Services T/A Myofascial Release Treatment Centers and MFR Seminars

14. Katake K (1961) The strength for tension and bursting of human fascia. Journal of Kyoto Professional Medical University 69: 484-488.

15. Juhan D (2003) Job's Body: A Handbook for Bodywork. Barrytown, New York 12507: Station Hill Press: 73.

16. Kessel R, Kardon R (1979) Tissues and Organs: A Text-Atlas of Scanning Electron Microscopy. San Francisco: W. H. Freeman and Company: 15.

17. Spock B, Parker S (1998) Dr Spock"s Baby and Child Care (7thedn) New York: Pocket Books

18. Oski F (1983) Don't Drink Your Milk (9thedn) Brushton, N.Y.: Teach Services.

19. Cohen R (2001) Milk A-Z. Oradell NJ: Argus Publishing.

20. Gillespie B (1999) Healing Your Child. Philadelphia: Productions for Children's Healing.

21. Gillespie B (2008) Case study in pediatric asthma: the corrective aspect of craniosacralfascial therapy. Explore(NY) 4: 48-51.

22. Gillespie B (2000) Brain Therapy for Children and Adults. Philadelphia: Productions for Children's Healing. 